\title{
Aortic elongation and bronchial splint for late bronchial complication after neonatal arch reconstruction
} \author{
Mass \\ From the ${ }^{\mathrm{a} D e p a r t m e n t}$ of Cardiac Surgery, ${ }^{\mathrm{b}}$ Department of Surgery, and ${ }^{\mathrm{c}}$ Department of Cardiology, Boston \\ Children's Hospital, Boston, Mass. \\ Disclosures: The authors reported no conflicts of interest. \\ The Journal policy requires editors and reviewers to disclose conflicts of interest and to decline handling or re- \\ viewing manuscripts for which they may have a conflict of interest. The editors and reviewers of this article \\ have no conflicts of interest. \\ Received for publication April 13, 2021; accepted for publication April 15, 2021; available ahead of print April \\ 24, 2021. \\ Address for reprints: Christopher W. Baird, MD, Department of Cardiac Surgery, Boston Children's Hospital, 300 \\ Longwood Ave, Boston, MA 02115 (E-mail: chris.baird@cardio.chboston.org). \\ JTCVS Techniques 2021;8:126-8 \\ 2666-2507 \\ Copyright $\odot 2021$ The Authors. Published by Elsevier Inc. on behalf of The American Association for Thoracic \\ Surgery. This is an open access article under the CC BY-NC-ND license (http://creativecommons.org/licenses/by- \\ nc-nd/4.0/). \\ https://doi.org/10.1016/j.xjtc.2021.04.014
}

Peter Chiu, MD, ${ }^{\mathrm{a}}$ Russell W. Jennings, MD, ${ }^{\mathrm{b}}$ Gerald Marx, MD, ${ }^{\mathrm{c}}$ and Christopher W. Baird, MD, ${ }^{\mathrm{a}}$ Boston,

Video clip is available online.

Aortic pathology may cause extrinsic compression of the airway, leading to tracheobronchomalacia and tracheobronchial compression. ${ }^{1}$ Left main stem bronchomalacia has been reported as a sequela following neonatal aortic arch reconstruction. ${ }^{2,3}$ We present a case of left main stem bronchomalacia and bronchial compression managed with aortic elongation and bronchial splinting 19 years after neonatal arch reconstruction and single ventricle palliation. This study did not require approval from the Institutional Review Board of Boston Children's Hospital. The subject provided informed written consent for publication of the study data.

\section{CASE REPORT}

Shortly after birth, the patient underwent stage 1 palliation with arch reconstruction using an aortic homograft for hypoplastic left heart syndrome followed by bidirectional Glenn and lateral tunnel fenestrated Fontan procedures. At age 13 years, he developed a chronic cough, and chest computed tomography (CT) scan demonstrated $60 \%$ narrowing of the proximal left main stem bronchus. However, the patient functioned well and was able to sing in choir, and thus he was managed expectantly. Pulmonary function tests at age 19 were normal, including forced expiratory volume at 1 second of $3.7 \mathrm{~L}$ (87\% of predicted) and forced vital capacity of $4.5 \mathrm{~L}$ ( $90 \%$ of predicted).

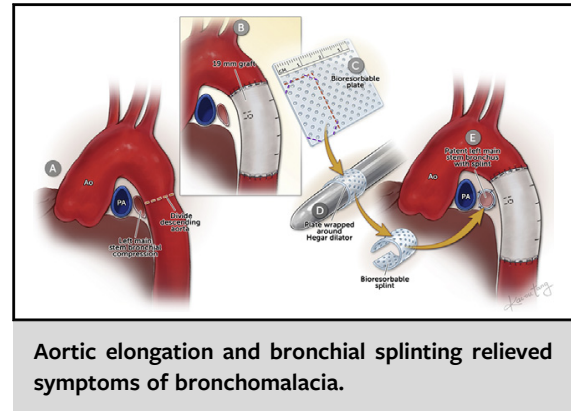

CENTRAL MESSAGE

Late bronchial compression by

the aorta with bronchomalacia

following neonatal arch recon-

struction may be treated with

aortic elongation and an external

bronchial splint.

See Commentaries on pages 129 and 132.
On follow-up, the patient reported a persistent cough keeping him awake at night. Dynamic CT scan revealed that the narrowing in the left main stem bronchus was dynamic and potentially caused by the aortic arch and proximal descending aorta stretching over the bronchus (Figure 1, $A$ and $B$ ). Bronchoscopy revealed $80 \%$ posterior compression, and so the patient was referred for surgery.

In the operating room, the patient was intubated with a double-lumen endotracheal tube adapted for recurrent laryngeal nerve monitoring using the dragonfly 2-channel EMG electrode (Neurovision Medical Products, Ventura, Calif) attached to the NIM 3.0 Nerve Monitoring System (Medtronic, Minneapolis, Minn). The left fourth interspace was entered through a posterolateral thoracotomy. Owing to the limited space under the aortic arch, aortopexy was deemed unsuitable. The left atrium and distal descending thoracic aorta were cannulated for left heart bypass. After clamping and dividing the aorta, extensive mobilization of the aortic arch and proximal descending aorta was necessary to relieve compressive effects on the left main stem bronchus (Figure 2, $A$ and $B$ ). Intraoperative bronchoscopy was then used to guide placement of an external bioresorbable splint (1.2-mm RapidSorb; DePuy Synthes, Raynham, Mass) that was molded around a Hegar dilator 

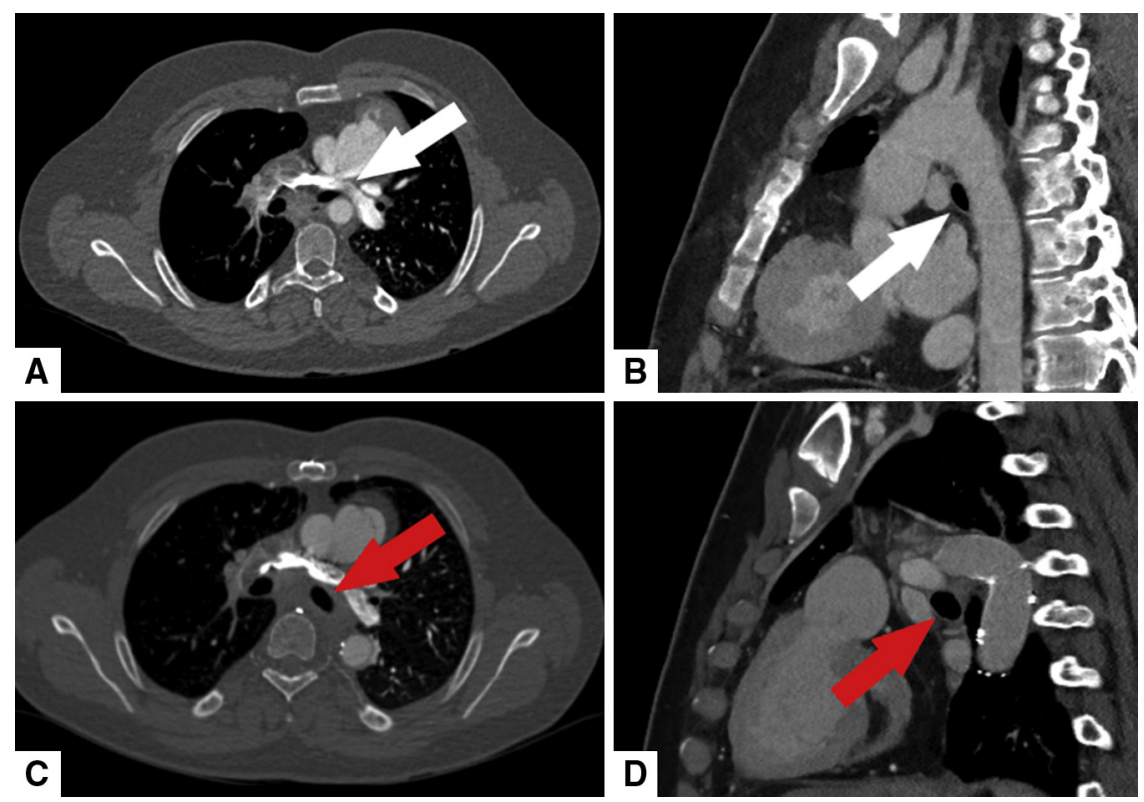

FIGURE 1. A and B, Preoperative computed tomography $(\mathrm{CT})$ angiogram demonstrating compression of the left main stem bronchus (white arrow) by the aorta stretching over it: (A) axial image; (B) sagittal image. C and D, Postoperative CT angiogram demonstrating a widely patent left main stem bronchus (red arrow) without vascular compression in the setting of the elongated aorta: (C) axial image; (D) sagittal image.

sized approximately $3 \mathrm{~mm}$ larger than the external diameter of the normal bronchus (Figure 2, $C$ and $D$, Video 1) and secured to the airway with nonabsorbable monofilament suture to hold the airway open (Figure 2, E). A 19-mm, 10-cm-long expanded polytetrafluoroethylene graft (PECA Labs, Pittsburgh, Pa) was used to reconstruct and

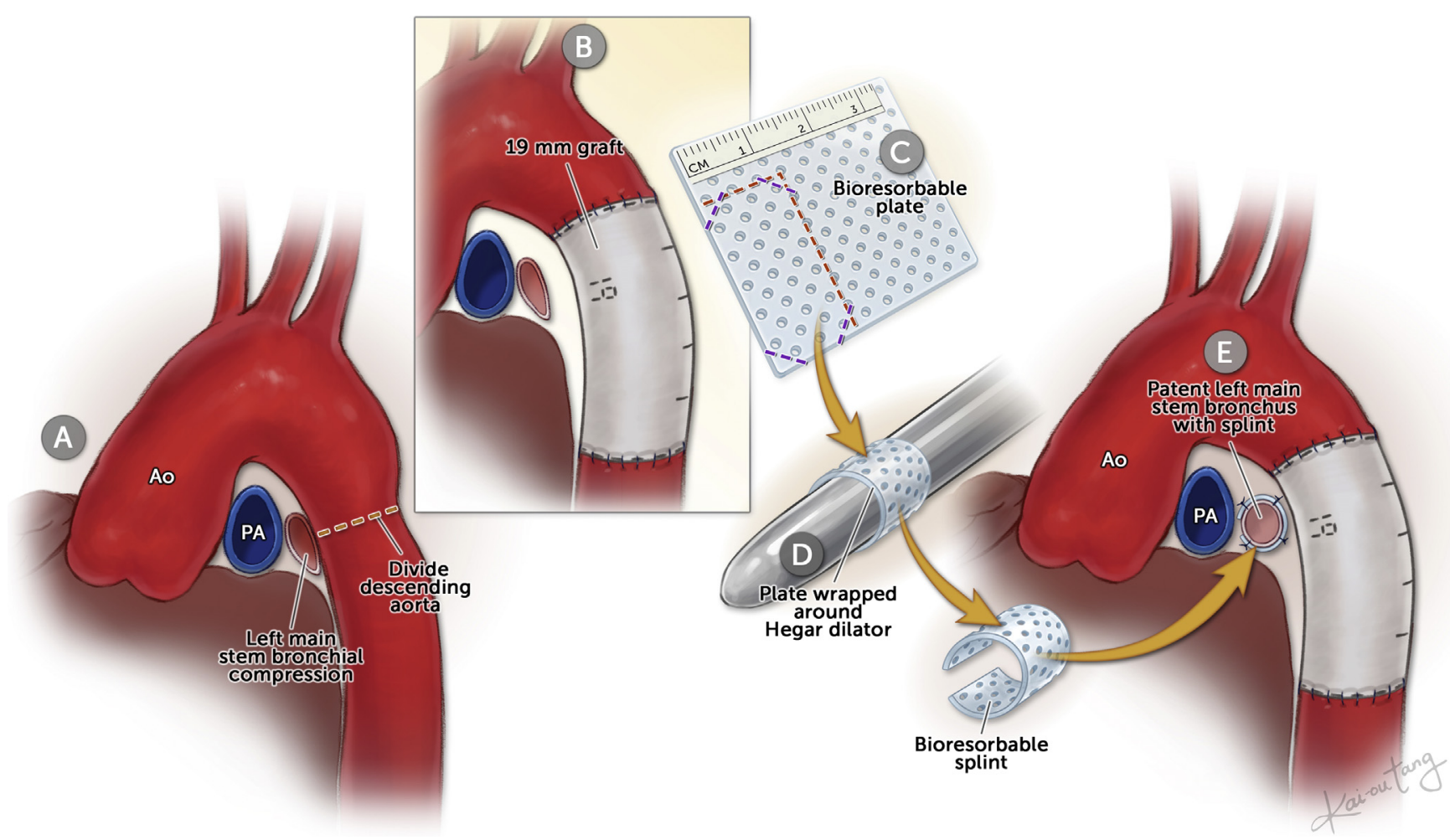

FIGURE 2. A, The descending aorta is seen to be compressing the left main stem bronchus. B, Division and elongation of the aorta with a 19-mm graft adequately relieved the compression on the bronchus. C, A bioresorbable plate was cut to size based on intraoperative findings. D, The plate was formed around a Hegar dilator. E, Once the splint was secured to the bronchus, intraoperative bronchoscopy revealed a widely patent airway. Ao, Aorta; $P A$, pulmonary artery. 


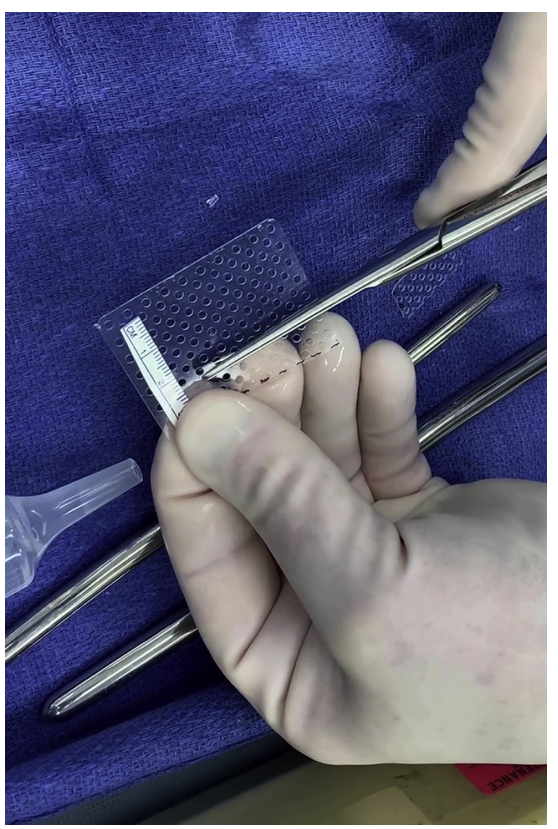

VIDEO 1. Preparation of a bronchial splint. The splint is fashioned to be $3 \mathrm{~mm}$ larger than the external diameter of the normal bronchus. The circumference of the bronchus and the length of the bronchus to be splinted then determine the length and width of the bioresorbable plate. Once the sharp edges are trimmed, the biosorbable plate is briefly placed in a hot water bath at $70^{\circ} \mathrm{C}$. When the plate has become malleable, it is formed around an appropriately sized Hegar dilator, with a small gap left to allow the splint to be fit around the bronchus. When the splint has cooled, it is easily slipped off the Hegar and retains its shape. Video available at: https://www.jtcvs. org/article/S2666-2507(21)00307-2/fulltext.

elongate the descending thoracic aorta. Intraoperative bronchoscopy with negative suction (Munoz maneuver) up to $-50 \mathrm{~mm} \mathrm{Hg}$ was performed, with no evidence of significant airway collapse. Postoperatively, the patient has had an uncomplicated recovery and was last seen 9 months postoperatively in clinic with no cough or respiratory symptoms. A postoperative $\mathrm{CT}$ angiogram demonstrated a widely patent left main stem bronchus (Figure 1, $C$ and $D$ ).

\section{DISCUSSION}

The incidence of left main stem bronchomalacia and bronchial compression following neonatal arch reconstruction is unknown. Cases reported in the literature have typically occurred shortly after arch reconstruction and are likely related to inadequate proximal and distal mobilization of the arch, causing the arch to stretch across the left main stem bronchus and resulting in bronchial compression. ${ }^{2,3}$ In many of these cases, anterior or posterior aortopexy and extensive mobilization are adequate to relieve the compression.

Mitchell and colleagues ${ }^{3}$ have reported aortic arch extension in the setting of left main stem bronchomalacia following repair of an interrupted aortic arch. In that case, aortic arch reconstruction through a median sternotomy required deep hypothermic circulatory arrest, and sleeve resection was also performed. The simplified operation that we present here avoids the need for either deep hypothermic circulatory arrest or bronchial resection, thus reducing the potential risk associated with the operation.

The use of bioresorbable splints in airway reconstruction has been reported previously. Whereas the group from the University of Michigan uses 3-dimensional-printed external splints made from $96 \%$ polycaprolactone $/ 4 \%$ hydroxyapatite, ${ }^{4,5}$ our group uses an off-the-shelf alternative that is resorbed in 12 months. The ability to customize the size and shape of the splint based on intraoperative bronchoscopy is a substantial advantage of our approach.

Late left main stem bronchomalacia with compression may be a sequela of neonatal aortic arch reconstruction attributable to altered mechanical properties that result in reduced elastic properties and impaired growth. In a patient presenting with late left main stem bronchomalacia 19 years after neonatal arch reconstruction, an aortic elongation procedure along with external support of the bronchus with a bioresorbable splint resulted in complete symptom resolution. Although our patient was an adult, the use of the PECA graft for the descending thoracic aorta may extend the benefit of this operation to children, as the graft may be subsequently balloon dilated as the child grows.

\section{References}

1. Backer CL, Mongé MC, Popescu AR, Eltayeb OM, Rastatter JC, Rigsby CK. Vascular rings. Semin Pediatr Surg. 2016;25:165-75.

2. Prêtre R, Turina MI. Relief of bronchial compression caused by a congenital heart defect by remodeling of the aortic arch. J Thorac Cardiovasc Surg. 2000;119: 173-4.

3. Mitchell MB, Campbell DN, Toews WH, Khan TZ. Autograft aortic arch extension and sleeve resection for bronchial compression after interrupted aortic arch repair. Ann Thorac Surg. 2002;73:1969-71.

4. Les AS, Ohye RG, Filbrun AG, Ghadimi Mahani M, Flanagan CL, Daniels RC, et al. 3D-printed, externally-implanted, bioresorbable airway splints for severe tracheobronchomalacia. Laryngoscope. 2019;129:1763-71.

5. Zopf DA, Hollister SJ, Nelson ME, Ohye RG, Green GE. Bioresorbable airway splint created with a three-dimensional printer. N Engl J Med. 2013;368:2043-5. 